\title{
Bronchus associated lymphoid tissue (BALT) in human lung: its distribution in smokers and non-smokers
}

\author{
I Richmond, G E Pritchard, T Ashcroft, A Avery, P A Corris, E H Walters
}

\begin{abstract}
Background-Bronchus associated lymphoid tissue (BALT) is a normal component of the lung's immune system in many animals and may be analogous to gut associated lymphoid tissue (GALT). This study aimed at assessing the nature and extent of BALT in human lung and determining whether its expression is induced within the human airway in response to smoking.

Methods-Paraffin embedded, formalin fixed full thickness bronchial wall sections were examined from 31 whole lung specimens derived from both smokers and non-smokers. Samples were taken from throughout the bronchial tree to include main stem bronchi, lobar bronchi and segmental bronchi, as well as first to third generation carinae. Standard $4 \mu \mathrm{m}$ step sections were stained by haematoxylin and eosin and immunocytochemical methods to show foci of BALT.
\end{abstract}

Results-Examination of 256 airway sites detected 46 foci of BALT. These differed from those described in other mammals in being distributed throughout the bronchial tree, in being found in relation to bronchial glandular epithelium as well as luminal bronchial epithelium, and in lacking any accompanying $M$ cells. Analysis by smoking status showed that the expression of BALT was significantly more common in smokers than non$\begin{array}{llllll}\text { smokers } & (82 \% & (14 / 17) & v & 14 \% & (2 / 14)\end{array}$ respectively).

Conclusions-The findings support the view that BALT in humans is an integral feature in a comparatively small proportion of lungs from non-smokers while being significantly more prominent in lungs from smokers. The tissue shows several important differences from that described in other mammals.

(Thorax 1993;48:1130-1134)

Bronchus associated lymphoid tissue (BALT) is a normal constitutive feature of the lung's immune system in a range of different animal species and may be analogous to gut associated lymphoid tissue (GALT), particularly Peyer's patches. ${ }^{12}$ In animals the features of
BALT have been described by Sminia $e t$ al as a follicular-like aggregation of lymphocytes (sometimes containing a germinal centre), high endothelial venules, and a specialised ${ }_{\infty}$ lymphoepithelium with intraepithelial lymphocytes and, in some species, non-ciliated $\mathrm{M}$ cells. ${ }^{3}$ In animals these BALT foci occur especially at airway bifurcations. Bronchus associated lymphoid tissue has been referred to as a normal component of the human lung in several immunological and pathological texts, ${ }^{45}$ but recent studies have questioned whether it is in fact a constitutive feature of human lung, suggesting that it may develop only after antigenic stimulation. ${ }^{67}$

We examined the nature and extent of BALT in human whole lung specimens from both smokers and non-smokers and assessed whether it is a reactive phenomenon or an integral feature of the lung.

\section{Methods}

Whole lung specimens were derived from 31 subjects. Fifteen lungs were obtained at pneumonectomy for lung carcinoma and one was obtained at necropsy from a subject with no history or macroscopic evidence of lung disease. In the remaining 16 cases the speci- 3 mens were donated for transplantation but $\delta$ had not been used because of parenchymal $₹$ contusion. The subjects from whom the lungs 9 were obtained included $17 \mathrm{men}$ and $14>$ women of mean (range) age 48.5 (14-89) 으․ years. Infection was excluded in the lungs $N$ donated for transplantation by Gram staining and microbiological culture of bronchoalveolar lavage specimens. None of the subjects $\underset{\omega}{\omega}$ had a history of atopy. The subjects were subdivided on the basis of smoking $\stackrel{\circ}{\circ}$ status into two groups. Seventeen subjects $\Phi_{\overparen{D}}$ were current smokers or ex-smokers of $<2 ?$ years' duration (smokers) and 14 had never 0 smoked or were ex-smokers of 2 or more $\underset{\otimes}{\stackrel{\nabla}{~}}$ years' duration (non-smokers). In all cases $\underset{\mathrm{D}}{\mathrm{D}}$ validation of smoking status was made by obtaining a definite history from the patient or, in the case of transplant donors, from a close relative.

Full thickness bronchial wall sections were taken from various sites throughout the bronchial tree including main stem bronchi, lobar bronchi, and segmental bronchi, as well as first to third generation carinae where the first generation carina is at the division of the 


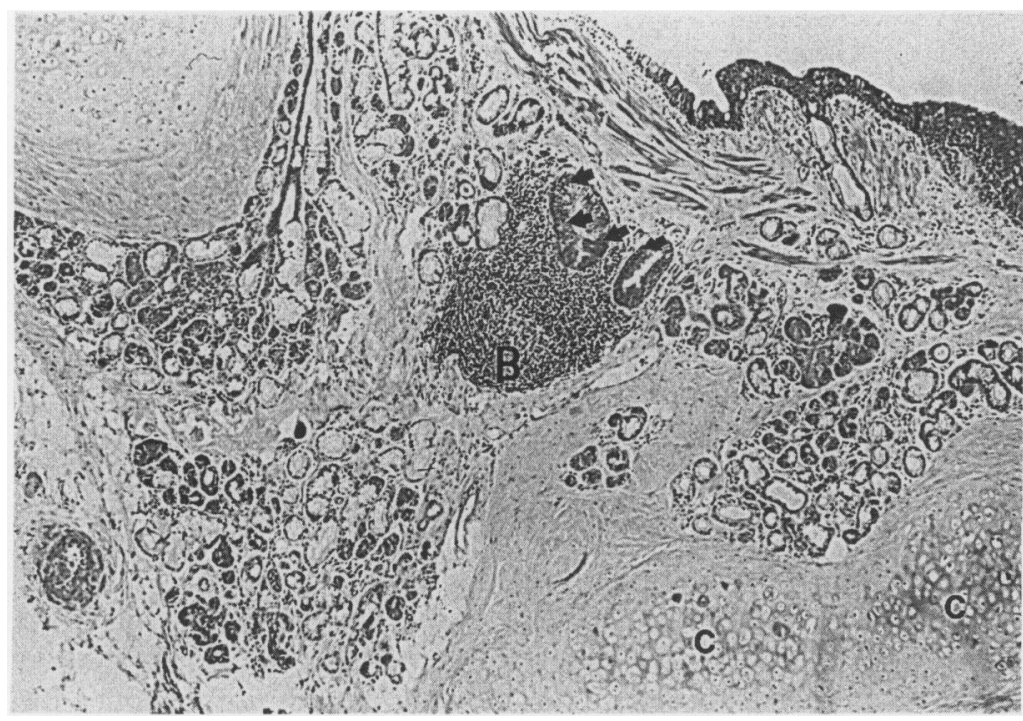

Figure 1 Low power photomicrograph of bronchial wall elements with a deeply situated focus of BALT (B) lying beneath the muscularis mucosae close to bronchial glands. Infiltration of the glandular epithelium by lymphocytes is just visible (arrows). Note the typical position close to junctions of cartilage bars (C) (haematoxylin and eosin).

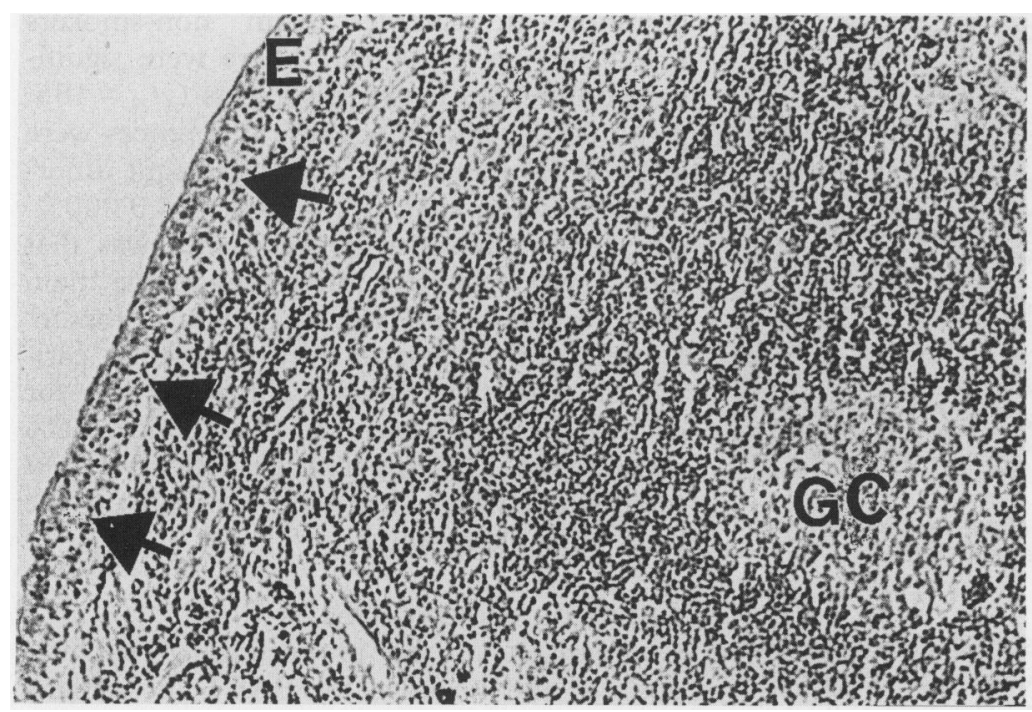

Figure 2 Photomicrograph of superficial focus of BALT containing a well defined germinal centre $(G C)$. Note the infiltration of the overlying lymphoepithelium $(E)$ by mature lymphocytes (arrows) (haemotoxylin and eosin).

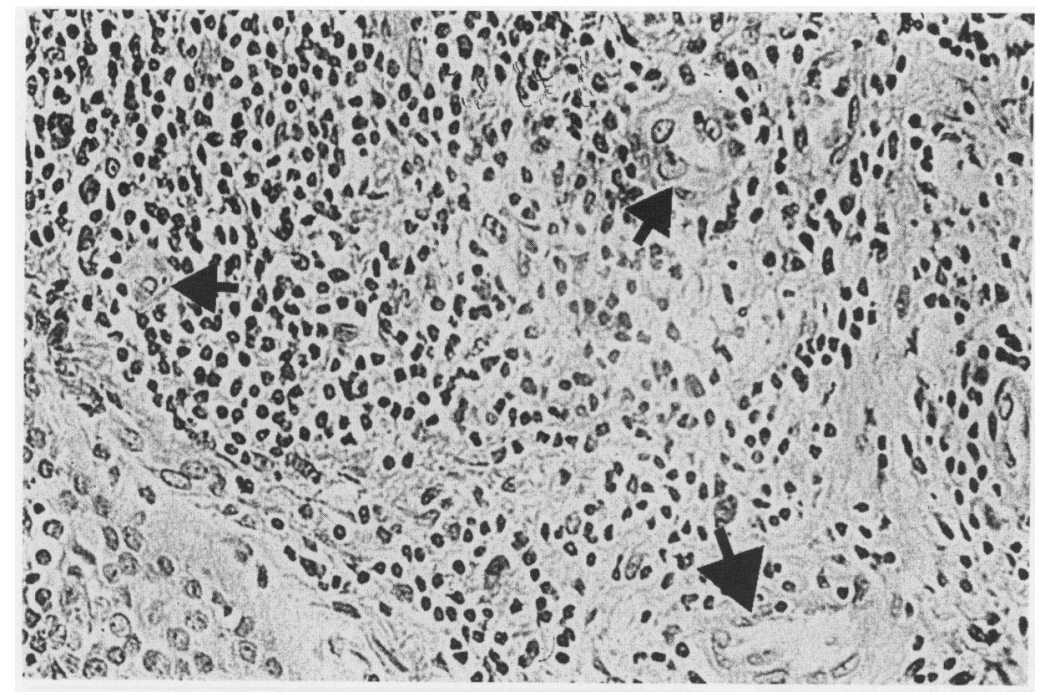

Figure 3 High power photomicrograph of high endothelial venules (arrows) at the margins of a focus of BALT (haematoxylin and eosin). trachea into main stem bronchi. In the pneumonectomy specimens bronchi from the lobe containing tumour were not sampled. The median number (range) of sites sampled in each lung was 9 (5-15). Tissue blocks from each site were fixed in formalin and embedded in paraffin wax. Four standard $4 \mu \mathrm{m}$ step sections $20 \mu \mathrm{m}$ apart were stained with haematoxylin and eosin. Parallel sections were stained with monoclonal antibodies to L26, UCHL-1, and CD35 (Dako, Cambridge) to identify B lymphocytes, $T$ lymphocytes, and dendritic cells respectively. Further sections were stained with monoclonal antibodies to surface immunoglobulins IgA, IgM, and IgG (Dako, Cambridge). A standard streptavidin biotin complex staining method was used for the immunocytochemistry. ${ }^{8}$ Pretreatment with trypsin was necessary with CD35 and the immunoglobulins.

Statistical analysis of anatomical differences in the distribution of BALT used a linear logistic model and a detailed statistical graphics package (Genstat, Lawes Agricultural Trust, UK). Statistical analysis of the distribution by smoking status in a population that was not normally distributed used Fisher's exact test with the aid of a standard statistical graphics package (Statgraphics, Statistical Graphics Corporation, Rockville, Maryland, USA).

\section{Results}

MORPHOLOGICAL APPEARANCES

Samples from a total of 256 airway sites were examined. Thirty seven contained lymphoid structures within the bronchial wall which we regarded as representing human BALT. These were defined microscopically as aggregates of mature lymphoid cells (more than 50 cells) closely related to bronchial epithelium of airway lumina or bronchial gland ducts and intimately associated with high endothelial venules. Infiltration of the overlying epithelium by lymphocytes was an integral feature of these foci. At most sites examined a solitary lymphoid aggregate was seen (median (range) $1(1-4)$ ). A total of 46 foci were thus identified. These structures consisted of aggregates of mature lymphoid cells (more than 50) which in 10 cases contained a well defined germinal centre. All 46 lymphoid aggregates contained prominent high endothelial venules. Fourteen of the foci were located directly beneath the bronchial epithelium, where accompanying intraepithelial lymphocytes were apparent. No specialised non-ciliated $M$ cells were seen in the epithelium. The remainder of the foci were situated more deeply within the bronchial wall beneath the muscularis mucosae. They were in close proximity to the epithelium lining bronchial glands and bronchial gland ducts, which in these cases contained abundant intraepithelial lymphocytes and were frequently situated at the junction of cartilage bars. Occasional plasma cells were present at the outer margin of these lymphoid structures, usually at the luminal margin. Despite 


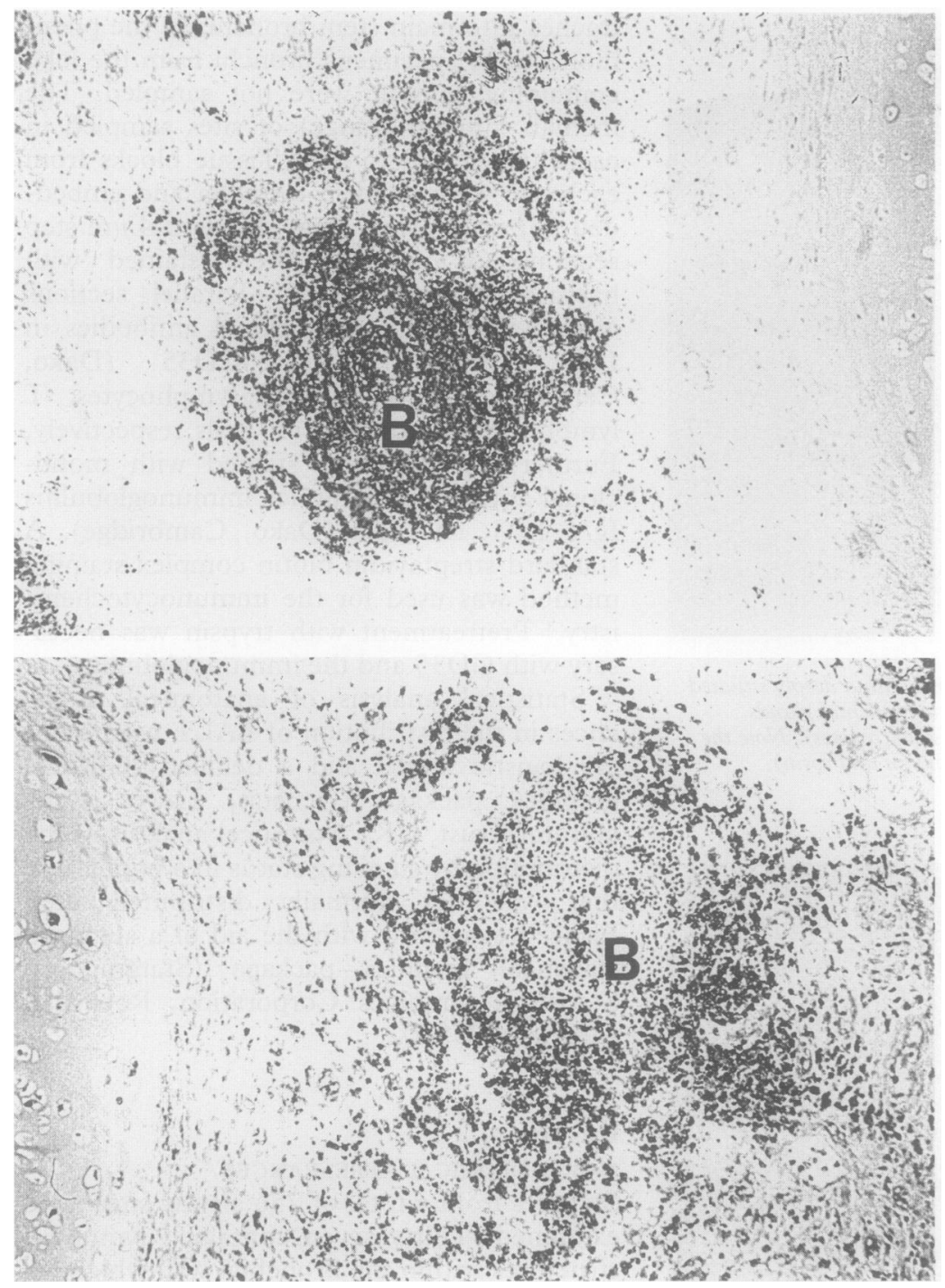

Figure 4 Photomicrographs of a focus of BALT (B) composed of a central core of $B$ cells positive for L26 surrounded by an irregular rim of T cells positive for UCHL-1.

examination of multiple step sections in each case no continuity between the superficial and deep foci was noted. Figures 1-3 show the appearances by light microscopy.

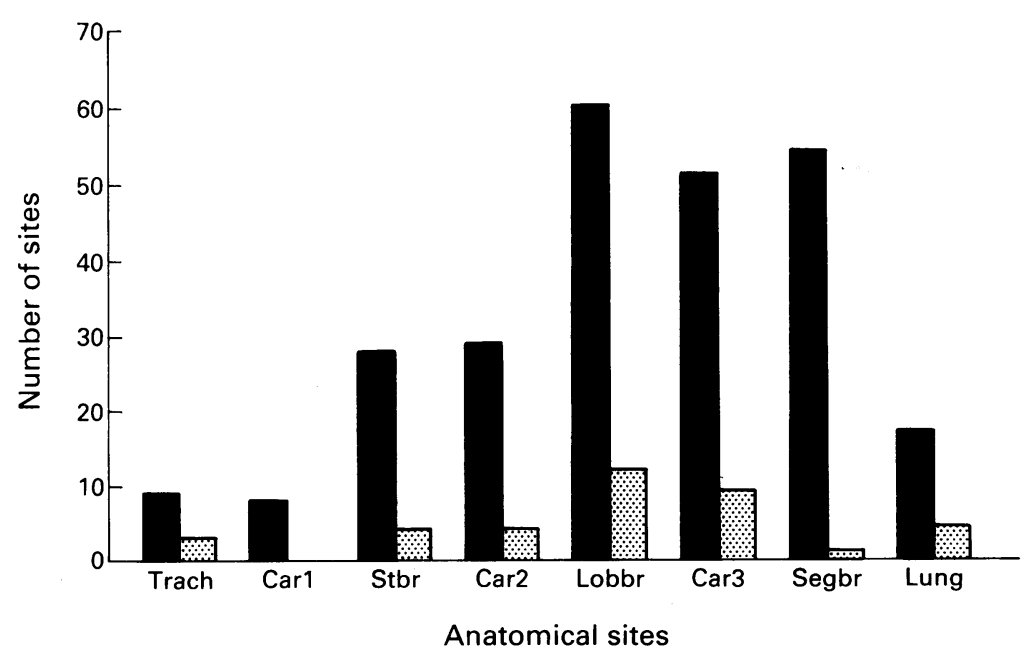

Figure 5 Anatomical distribution of BALT. Histogram of total number of sites sampled (घ)and number positive for BALT (.). (Trach = trachea, Car 1, Car 2 and Car $3=$ first, second, and third generation carinae respectively, Stbr $=$ main stem bronchus, Lobbr = lobar bronchus, Segbr = segmental bronchus, and Lung = peripheral lung containing bronchioles).

\section{IMMUNOCYTOCHEMISTRY}

Immunocytochemistry showed the lymphoid aggregates to be composed of a core of L26 positive B lymphocytes surrounded by a rim of UCHL-1 positive T lymphocytes (fig 4). Where germinal centres were identified CD35 positive dendritic cells were noted. Staining of cell surface immunoglobulins showed only occasional lymphoid cells with surface $\operatorname{IgA}$ or $\operatorname{IgM}$ within the BALT foci; no cells positive for surface IgG were noted. In some of the more superficial foci cells positive for surface IgA were identified predominantly beneath the luminal epithelium.

\section{DISTRIBUTION OF FOCI}

Comparison of the distribution of the lymphoid structures by anatomical site showed them to be distributed throughout the bronchial tree with no predilection for either the airways or carinae examined (fig 5). Foci were, however, disproportionately uncommon in the segmental bronchi. The relative prevalence of BALT was analysed by using a linear logistic model. The tissue was less common in samples from non-smokers $\left(\chi_{1}^{2}=56 \cdot 7, \mathrm{p}<0 \cdot 0005\right)$. There were significant differences between subjects $\left(\chi_{29}^{2}=185\right.$, $\mathrm{p}<0.0005)$, and after these differences were allowed for there were also significant differences between sites $\left(\chi^{2}{ }_{5}=28.5, \mathrm{p}<0.0005\right)$. The main difference between sites was that BALT was relatively infrequent in the main stem bronchi and the segmental bronchi. Comparison of first to third generation carinae showed that the percentage of foci for each of these sites was $0 \%, 15 \cdot 4 \%$ and $19.6 \%$ respectively. This apparent gradation was not maintained when sites were divided on the basis of smoking status.

\section{EFFECT OF SMOKING STATUS}

Comparison of the proportion of subjects positive and negative for BALT in smokers and non-smokers (as defined earlier) showed the tissue to be present in $14 \%$ of lungs from non-smokers (2/14) as compared with $82 \%$ of lungs from smokers (14/17). There was a significantly greater proportion of subjects positive for BALT in the smoking group than in the non-smoking group, as shown in the table. This difference was significant (Fisher's exact test, $p<0.0005)$. The between site differences referred to above differed between smokers and non-smokers $\left(\chi^{2}{ }_{5}=14.9, \mathrm{p}<\right.$ $0.025)$. Germinal centres were identified only in the BALT foci from the smokers (in a total of six subjects all but one were current smok-

Comparison of subjects positive and negative for bronchus associated lymphoid tissue by smoking status

\begin{tabular}{lcc}
\hline & \multicolumn{2}{c}{ Bronchus associated lymphoid tissue } \\
\cline { 2 - 3 } & Positive & Negative \\
\hline Smokers $(\mathrm{n}=17)$ & 14 & 3 \\
Non-smokers $(\mathrm{n}=14)$ & 2 & 12 \\
Total & 16 & 15 \\
\hline
\end{tabular}

Fisher's exact test, $\mathrm{p}<0.0005$ for difference between smokers and non-smokers. 
ers, with the other subject having stopped smoking only seven months previously).

\section{Discussion}

In the respiratory tract lymphoid aggregates with an accompanying lymphoepithelium have been termed bronchus associated lymphoid tissue. Such structures have been compared with the organised lymphoid tissue of the gut, which includes Peyer's patches. ${ }^{12}$ The term bronchus associated lymphoid tissue or BALT was introduced by Bienenstock et al, who studied the morphological and functional characteristics of the tissue predominantly in rabbits. In rabbits, BALT is a constituent of the lung, being found throughout the airway, particularly at airway bifurcations. $^{9-11}$ These studies highlighted the similarities to gut associated lymphoid tissue. More recent reviews, however, have detailed several major differences between bronchus associated and gut associated lymphoid tissue, including a paucity of germinal centres, less clear compartmentalisation of the lymphoid structure, and a lack of $M$ cells (specialised non-ciliated epithelial or membraneous cells concerned with antigen uptake) in the bronchial epithelium. ${ }^{3}$

Comparative studies of different nonhuman mammalian species have shown wide variations in the frequency of BALT, which is present in all rabbits and rats but only a third of pigs and is completely absent in cats. ${ }^{6}$ This implies that the tissue is not necessarily a constituent of the lung in all animal species but perhaps develops in response to antigenic or other inflammatory stimuli. Similarly, although BALT has been described as a normal component of the human lung in several standard texts, ${ }^{45}$ its features are ill defined. Indeed, Pabst and Gehrke failed to find any foci in whole lungs derived from 34 subjects at necropsy who had no history of chronic lung disease. ${ }^{6}$ Although they implied that BALT is not a normal feature of human lung, Pabst and Gehrke did not exclude the possibility that the tissue could develop in stimulated human lung. ${ }^{6}$ In fact, several studies have reported the presence of BALT or similar foci in cases of recurrent or chronic pneumonia, bronchiectasis, and chronic bronchitis. ${ }^{12-15}$

Our study outlines the appearances of BALT or similar tissue in human lung and lends support to the view that it can be induced in response to inhaled particulate antigens in cigarette smoke. The tissue we described shows several important differences from the early accounts of BALT in rabbits. ${ }^{9-11}$ Unlike the rabbit model, human BALT was found not only in relation to the luminal bronchial epithelium but also in relation to the deeper bronchial glands and ducts. Interestingly, a recent study of the peripheral lung of smokers showed foci of BALT distributed in the outer, deeper aspect of the airway walls in direct contradistinction to the results of earlier studies in animals. ${ }^{16}$ Perhaps another major morphological difference between the tissue we describe and that described in other mammals is its diffuse distribution. Though BALT is found throughout the bronchial tree in humans, it is predominantly found in the carinae in rabbits. ${ }^{9}$ Furthermore, although we found lymphocyte infiltration of the overlying epithelium in relation to the foci, we saw no M cells; however, examination of multiple serial sections through each focus would be necessary to assess accurately whether $M$ cells were present. These differences emphasise the need for caution in interpreting the role of BALT in antigen uptake and rejection of lung transplants when experimental animals are used. ${ }^{17}$

Our study provides direct evidence that BALT is inducible in humans because it occurred in our cases in response to cigarette smoke. When the donor subjects were divided on the basis of smoking status we took the well documented reversibility of inflammation in smokers after smoking cessation $^{18-20}$ into account in defining two years of no smoking as the cut off point. This finding by no means precludes the presence of BALT as an integral feature in normal human lungs; indeed we found BALT in $14 \%$ of the lungs from non-smokers, which is in contrast to the results of Pabst and Gehrke in which no tissue was found in 34 normal lungs at necropsy. ${ }^{6}$ Obviously one can argue about what constitutes normal lung and that truly normal lung is difficult to obtain in studies of this sort. As the airway is a mucosal surface constantly being bombarded by inflammatory stimuli it is perhaps not surprising that occasional BALT foci will be identified even in presumed normal lung. A study of lungs from subjects of different ages would be necessary to determine to what extent BALT was an integral feature of the lung's immune system.

It is interesting to speculate about which factors determine the formation of BALT. Whether the tissue forms as a direct response to smoking itself or to secondary airway inflammation is unclear. Certainly in three of the 17 smokers no BALT foci were seen, although more foci might have been identified had more sites been examined. Similarly, in two of the 14 non-smokers BALT foci were seen. The extent of BALT in different mammals may be related to efficiency of the clearance mechanisms in keeping antigen, especially particulate antigen, away from the bronchial epithelium.

In summary, this study details the distribution of BALT in human lungs. We provide evidence for it being present in the lung of non-smokers and for it being induced in response to inhaled antigen in cigarette smoke.

1 Bienenstock J. Immunology of the lung and upper respiratory tract. New York: McGraw Hill, 1984.

2 Bienenstock J, Befus D. Gut and bronchus-associated lymphoid tissue. Am $\mathcal{F}$ Anat 1984;170:437-45.

3 Sminia T, van der Brugge-Gamelkoorn GJ, Jeurissen SHM. Structure and function of bronchus-associated lymphoid tissue (BALT). Crit Rev Immunol 1989;9: 119-51. 
4 Colby TV. Lymphoproliferative diseases. In: Dail DH, Hammar SP, eds. Pulmonary pathology: Berlin: SpringerVerlag, 1988;711-26.

5 Roitt IM, Brostoff J, Male DK. Immunology. London: Gower, 1985.

6 Pabst $R$, Gehrke I. Is the bronchus-associated lymphoid tissue (BALT) an integral structure of lung in normal mammals, including humans? Am $\mathcal{F}$ Respir Cell Mol Biol 1990;3:131-5.

7 Pabst R. Is BALT a major component of the human lung immune system? Immunol Today 1992;13(4):119-21.

8 Guersdon JL, Ternynck T, Avraneas S. The use of avidin biotin interaction in immunoenzymatic techniques. f Histochem Cytochem 1979;27:1131.

9 Beinenstock J, Johnston N, Perey DYE. Bronchial lymphoid tissue. I. Morphological characteristics. Lab Invest 1973;28:686-92.

10 Beinenstock J, Johnston N, Perey DYE. Bronchial lymphoid tissue. II. Functional characteristics. Lab Invest 1973;28:693-8.

11 McDermott MR, Befus AD, Beinenstock J. The structura basis for immunity in the respiratory tract. Int Rev Exp Pathol 1982;23:47-112.

12 Meuwissen HJ, Hussain M. Bronchus-associated lymphoid tissue in human lung: correlation of hyperplasia with chronic lung disease. Clin Immunol Immunopathol 1982;23:548-61.

13 Emery JL, Dinsdale F. The post-natal development of lymphoreticular aggregates and lymph nodes in infants lungs. $\mathcal{f}$ Clin Pathol 1973;26:539-45.

14 Deventhal S, Pabst $R$. Bronchus-associated lymphoid tissue (BALT) is not an integral structure in humans but may occur in chronic inflammation. Eur Respir $\mathcal{f}$ [Suppl] 1991:217.

15 Sato A, Chida K, Iwata M, Hayakawa H. Study of bronchus-associated lymphoid tissue in patients with diffuse panbronchiolitis. Am Rev Respir Dis 1992;146: 473-8.

16 Bosken CH, Hards J, Gatter K, Hogg JC. Characterization of the inflammatory reaction in the peripheral airways of cigarette smokers using immunocytochemistry. Am Rev Respir Dis 1992;145:911-7.

17 Prop J, Wildevur CRH, Nieuwenhuis P. Lung allograft rejection in the rat. Specific immunological properties of lung grafts. Transplantation 1985;40:126-31.

18 Mili F, Flanders WD, Boring JR, Annest JL, Destefano F. The association of race, cigarette smoking and smoking cessation on measures of the immune system in middle aged men. Clin Immunol Immunopathol 1991;59.

19 Tollerud DJ, Clark JW, Morris-Brown L, Neuland CY, Mann DL, Pankiw-Trost LK. The effect of cigarette smoking on T-cell subsets. Am Rev Respir Dis 1989; 139:1446-51.

20 Tollerud DJ, Morris-Brown L, Blattner WA, Mann CY, Pankiw-Trost, Hoover RN. T-cell subsets in healthy black smokers and non-smokers. Am Rev Respir Dis 1991;144:612-6. 